\title{
PEMBERDAYAAN KELOMPOK TANI SAWAH PAYO KABUPATEN TANAH DATAR MELALUI TEKNIK PEMANGKASAN TANAMAN KAKAO
}

\author{
Yulmira Yanti*), Hasmiandy Hamid, Reflin dan Noveriza Hermeria \\ Program Studi Proteksi Tanaman Fakultas Pertanian Universitas Andalas \\ *)Email: mira23@gr.unand.ac.id; yy.anthie79@gmail.com
}

\begin{abstract}
ABSTRAK
Kakao (Theobroma cacao L.) merupakan salah satu jenis tanaman perkebunan yang terus mendapat perhatian untuk dikembangkan. Salah satu daerah di Sumatera Barat yang terbilang sebagai sentral perkebunan kakao adalah Nagari Gunung Rajo, Kabupaten Tanah Datar. Namun dalam pembudidayaan seringkali mendapat permasalahan seperti yang dihadapi kelompok Tani Sawah Payo dalam memproduksi biji kakao yaitu pohon kakao yang telah menua dan rusak akibat serangan hama penyakit. Untuk mengatasi masalah tersebut perlu adanya usaha intensifikasi yang dapat mengurangi serangan hama dan penyakit sehingga produksi dari kakao tersebut terus meningkat. Tujuan dari kegiatan pemberdayaan kelompok tani ini adalah memberikan pengetahuan tentang teknik dan proses pemangkasan tanaman budidaya kakao yang baik dan benar sesuai dengan prosedur budidaya yang seharusnya agar dapat meningkatkan hasil produktivitas dari tanaman tersebut. Metode yang digunakan dalam kegiatan adalah metode pendekatan secara langsung dan tidak langsung. Metode pendekatan secara langsung dengan melakukan wawancara terhadap masyarakat Nagari Gunung Rajo serta dengan mengadakan sosialisasi dan demonstrasi langsung di lapangan. Metode secara tidak langsung yang dilakukan adalah observasi. Observasi merupakan pengamatan yang dilakukan guna mengetahui kebiasaan. Hasil yang diperoleh dari kegiatan pemberdayaan adalah masyarakat khususnya kelompok tani Sawah Payo memiliki pengetahuan yang lebih terhadap cara budidaya tanaman kakao yang baik dan benar, mengetahui kapan waktu yang tepat untuk dilakukan pemangkasan serta jenis pemangkasan seperti apa yang diperlukan sehingga dapat meningkatkan hasil produksi dari kakao itu sendiri. Kegiatan ini sangat membantu masyarakat dalam mengatasi setiap permasalahan yang ditemukan dalam budidaya tanaman kakao tersebut.
\end{abstract}

Kata Kunci: pemberdayaan, pemeliharaan, pemangkasan, kakao

\section{Empowerment of Payo Rice Farm Group Payo District in Cocoa Pruning Training}

\begin{abstract}
Cocoa (Theobroma cacao L.) is one types of plantation plants that receive constant attention to develop. One of the areas in West Sumatra that emerged as the center of the cocoa plantation was nagari mount rajo, a flatland district. But in its cultivation, it often has the same problem that payo farm groups have in producing cocoa beans, cocoa trees that have aged and been destroyed by disease pests. An intensified effort to overcome the problem would be to reduce pests and disease attacks, and the cocoa production would continue to increase. The purpose of the farm group's empowerment activity is to give knowledge of the techniques and processes of pruning good and proper cocoa cultivation plants according to the proper procedure in order to produce productivity results from the plant. The method used in this activity is a direct and indirect approach. A direct approach by conducting an interview with the nagari people of mount rajo and by socializing and live demonstrations in the field. The indirect method of doing this is observation. Observation is an observation made to know the habbit. The result of empowering activities is that communities especially payo farm groups have a greater knowledge of how to cultivate good and true cocoa plants, knowing when the time is right to do the pruning and the kind of pruning that is necessary so $\mathrm{s}$ to increase the production of the cocoa. This activity has been a tremendous help to the community in solving every problem found in the cultivation of the cocoa plant.
\end{abstract}

Keywords: empowerment, maintenance, pruning, cocoa 


\section{PENDAHULUAN}

Kakao merupakan salah satu komoditas unggulan penting Indonesia yang merupakan sumber kehidupan bagi sekitar 1,4 juta rumah tangga. Secara nasional, perkebunan kakao memberikan kontribusi ekspor keempat terbesar setelah sawit, karet, dan kopi. Tahun 2013, luas perkebunan kakao Indonesia mencapai 1,74 juta ha dengan volume produksi 720.862 ton biji kakao diperkirakan 95 persen perkebunan kakao dikelola oleh rakyat. Dari jumlah ini sebesar 414.092 ton atau sekitar 57,4 persen diekspor dengan nilai ekspor sekitar USD1,15 miliar (Kementerian Pertanian, 2015). Komoditas kakao dikembangkan mengingat peranannya dalam mendukung perekonomian nasional yang sangat penting.

Indonesia merupakan negara terbesar ketiga dalam produksi kakao setelah Pantai Gading dan Gana yang berkontribusi sekitar 16\% dari produksi kakao dunia. Pemerintah Provinsi Sumatera Barat menilai komoditi kakao terbukti mampu memberikan penghasilan yang menjanjikan kepada petani, terutama ketika harga kakao terus merangkak sehingga pendapatan petani juga meningkat secara signifikan. Kondisi ini didukung oleh ketersediaan lahan yang masih luas. Menurut Pusat Penelitian Kakao dan Kopi Indonesia (2013). Potensi lahan yang dapat digunakan untuk budidaya kakao di Sumatera Barat mencapai 3,9 juta Ha, sedangkan yang baru diusahakan hanya 145.735 Ha. Beberapa Pemda Kabupaten dan Kota yang sudah mencanangkan untuk mengembangkan komoditi ini adalah: Sawahlunto, Payakumbuh, Pasaman, Pasaman Barat, Agam dan Padang Pariaman. Untuk itu sampai tahun 2013, pemerintah provinsi Sumatera Barat telah membagikan 2,5 juta bibit kepada petani kakao secara gratis, dengan demikian diharapkan pemerintah kabupaten dan kota terangsang untuk mengembangkan kakao dalam rangka meningkatkan ekonomi kerakyatan (Khairul, et al., 2018).

Situasi perdagangan kakao dunia beberapa tahun terakhir sering mengalami defisit, sehingga berdampak pada harga kakao dunia yang relatif stabil pada tingkat yang tinggi. Kondisi ini merupakan suatu peluang yang memiliki prospek cerah untuk secepatnya komoditas kakao dikembangkan guna meningkatkan kesejahteraan masyarakat. Dalam kurun satu dasawarsa terakhir ini meskipun luas areal perkebunan kakao terus meningkat dengan rata-rata peningkatan sekitar 7,9 persen per tahun, dan peningkatan produksinya rata-rata mencapai 7,2 persen per tahun ternyata tingkat produktivitasnya cenderung menurun dengan rata-rata sekitar 0,7 persen per tahun (Murniningtyas, 2011).

Penanaman kakao tidak harus monokultur dalam pembudidayaannya, tetapi dapat ditanam bersama dengan tanaman lain sebagai tumpang sari atau pun dengan tanaman penaung sehingga petani memperoleh keuntungan ganda (Baon dan Abdoellah, 2004). Namun, saat ini produktivitas tanaman kakao rata-rata baru mencapai 591.18 $\mathrm{kg} /$ ha sedangkan potensi produktivitas dapat mencapai 1.5 -3 ton/ha (Kardiyono, 2010). Untuk menjaga agar produktivitas kakao meningkat dapat dilakukan pemeliharaan tanaman yang salah satu aspeknya adalah pemangkasan.

Pemangkasan merupakan salah satu teknik budidaya yang penting dilakukan dalam pemeliharaan tanaman kakao dengan cara membuang tunas-tunas liar seperti cabang-cabang yang tidak produktif, cabang sakit, cabang kering, dan cabang 
overlapping terutama dalam hal mengatur iklim mikro yang tepat bagi pertumbuhan bunga dan buah atau untuk mengatur jumlah dan sebaran daun (Prawoto, 2008) sehingga tanaman kakao dapat memiliki kondisi yang baik untuk pertumbuhannya. Pengaruh pemangkasan pada tanaman kakao berdampak besar, yaitu menurunkan kelembaban kebun, memperoleh iklim mikro yang sehat dan produksi tinggi, serta pemangkasan yang efektif dan tepat waktu dapat membantu pengontrolan penyakit tanaman kakao (Wood and Lass, 1985).

Pemangkasan yang tidak optimal menyebabkan rendahnya produktivitas buah kakao. Pemangkasan merupakan aspek budidaya yang berpengaruh secara langsung terhadap produksi dan produktivitas buah kakao. Menurut Pujiyanto (2008) minimumnya pemangkasan dalam jangka waktu yang panjang dapat menyebabkan bentuk tajuk tidak teratur. Menurut Nasaruddin (2009), pemangkasan ditujukan pada pembentukan cabang yang seimbang dan pertumbuhan vegetatif yang baik. Pohon pelindung juga dilakukan pemangkasan agar percabangan dan daunnya tumbuh tinggi dan baik.

Pemangkasan ada beberapa macam yaitu: a) Pangkas bentuk, dilakukan umur 1 tahun setelah muncul cabang primer (jorquette) atau sampai umur 2 tahun dengan meninggalkan 3 cabang primer yang baik dan letaknya simetris. b) Pangkas pemeliharaan, bertujuan mengurangi pertumbuhan vegetatif yang berlebihan dengan cara menghilangkan tunas air (wiwilan) pada batang pokok atau cabangnya. c) Pangkas produksi, bertujuan agar sinar dapat masuk tetapi tidak secara langsung sehingga bunga dapat terbentuk. Pangkas ini tergantung keadaan dan musim, sehingga ada pangkas berat pada musim hujan dan pangkas ringan pada musim kemarau. d) Pangkas restorasi, memotong bagian tanaman yang rusak dan memelihara tunas air atau dapat dilakukan dengan side budding.

Tindakan pemangkasan diharapkan akan mampu memperbaiki kondisi kebun dalam menerima sinar matahari dan sirkulasi udara di dalam kebun menjadi lebih baik dan terhindar dari serangan hama dan penyakit, sehingga merangsang pertumbuhan bunga dan buah dan akan meningkatkan produksi tanaman. Hal ini sesuai dengan pernyataan Karmawati et al., (2010) bahwa pemanfaatan pemangkasan merupakan suatu usaha meningkatkan produksi dan mempertahankan umur ekonomis tanaman. Pemangkasan secara umum bertujuan untuk memperoleh pertumbuhan tajuk yang seimbang dan kokoh, mengurangi kelembaban sehingga aman dari serangan hama dan penyakit, memudahkan pelaksanaan panen dan pemeliharaan serta mendapatkan produksi yang tinggi.

Nagari Gunung Rajo merupakan salah satu Nagari di kecamatan Batipuh yang masyarakatnya pada umumnya bermata pencaharian sebagai petani. Selain bertanam padi petani juga banyak mengandalkan penghasilan dari usaha budidaya tanaman kakao. Namun penghasilan yang didapat sering tidak menentu dan bahkan juga tidak jarang mengalami penurunan dari tahun ke tahun akibat permasalahan dalam budidaya, seperti serangan hama dan penyakit, pemeliharaan yang kurang diperhatikan, tidak dilakukan pemangkasan sehingga tanaman tidak mendapatkan cahaya matahari dalam pertumbuhannya. Untuk itu perlu dilakukan kegiatan ini untuk memberikan pemahaman kepada kelompok tani dan masyarakat sekitarnya tentang budidaya tanaman kakao, serta cara dan bentuk pemangkasan yang dapat dilakukan. Sosialisasi 
ini akan sangat membantu petani dalam pengembangan budidaya tanaman kakao, dimana dengan kegiatan ini akan meningkatkan pengetahuan dan keterampilan petani terutama dalam masalah pemeliharaan kakao. Hasil yang diharapkan dari kegiatan ini adalah peningkatan pemahaman dan pengetahuan petani kakao dalam melakukan budidaya dan melakukan pemeliharaan terhadap tanaman kakao yang dibudidayakan, sehingga produksi tanaman menjadi meningkat.

\section{METODE}

Kegiatan pemberdayaan kelompok tani melalui program pengabdian masyarakat dilaksanakan pada tanggal 11 dan 21 Desember 2019 di Nagari Gunung Rajo Kecamatan Batipuh Kabupaten Tanah Datar, Sumatera Barat. Tujuan dari kegiatan pemberdayaan kelompok tani ini adalah memberikan pengetahuan tentang teknik dan proses pemangkasan tanaman budidaya kakao yang baik dan benar sesuai dengan prosedur budidaya yang seharusnya agar dapat meningkatkan hasil produktivitas dari tanaman tersebut. Sasaran khalayak atau peserta dari kegiatan ini yaitu kelompok tani Sawah Payo dan masyarakat Nagari Gunung Rajo yang memiliki perkebunan kakao. Metode yang digunakan dalam kegiatan ini adalah metode pendekatan secara langsung dan tidak langsung. Metode pendekatan secara langsung yaitu dengan melakukan wawancara terhadap masyarakat Nagari Gunung Rajo serta dengan mengadakan sosialisasi dan demonstrasi langsung di lapangan. Metode secara tidak langsung yang dilakukan yaitu dengan cara observasi. Observasi merupakan pengamatan yang dilakukan guna mengetahui kebiasaan yang dilakukan masyarakat setempat. Kegiatan dimulai dengan pemberian materi oleh narasumber dan dilanjutkan dengan diskusi perihal teknik dan jenis pemangkasan yang baik dan benar. Sedangkan kegiatan demonstrasi dilakukan setelah kegiatan sosialisasi dan diskusi selesai diberikan, sehingga masyarakat menjadi lebih paham mengenai bagaimana proses pemangkasan tersebut. Demonstrasi dilakukan langsung oleh dosen dan mahasiswa Fakultas Pertanian yang merupakan anggota tim dari kegiatan pengabdian masyarakat ini.

\section{HASIL DAN PEMBAHASAN}

\section{Penyuluhan dan Diskusi}

Sosialisasi dan diskusi dengan masyarakat tentang budidaya dan teknik pemangkasan tanaman kakao yang baik dan benar pada pertemuan pertama dilakukan di rumah salah seorang anggota Kelompok Tani Sawah Payo dengan melibatkan Sekretaris Nagari Gunung Rajo Ketua Kelompok Tani Sawah Payo dan masyarakat setempat (Gambar 1). Kegiatan diskusi berjalan dengan baik, masyarakat sangat antusias mendengarkan dan bertanya kepada pemateri mengenai materi yang disampaikan sehingga masyarakat jadi paham dan dapat menambah pemahamannya yang selama ini masih terbilang kurang dalam budidaya tanaman kakao. Kegiatan Penyuluhan dan demonstrasi memberikan dampak yang nyata bagi masyarakat karena 
mereka langsung praktik, kegiatan serupa sesuai dengan kegiatan yang telah dilaksanakan di jorong Ngu Ngun (Yanti et al .,2019)

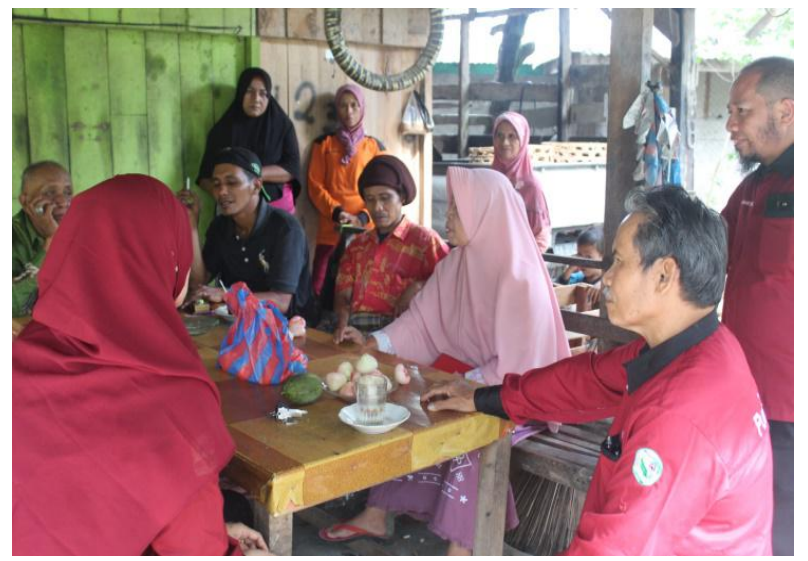

Gambar 1. Diskusi bersama masyarakat mengenai budidaya tanaman kakao

Adapun materi yang diberikan ialah: (1) Cara budidaya tanaman kakao yang baik dan benar sesuai prosedur budidaya yang seharusnya; (2). Cara pemangkasan dan bentuk- bentuk pemangkasan yang dapat dilakukan; (3) Bagian-bagian dari tanaman kakao yang dapat di pangkas (Gambar 2).

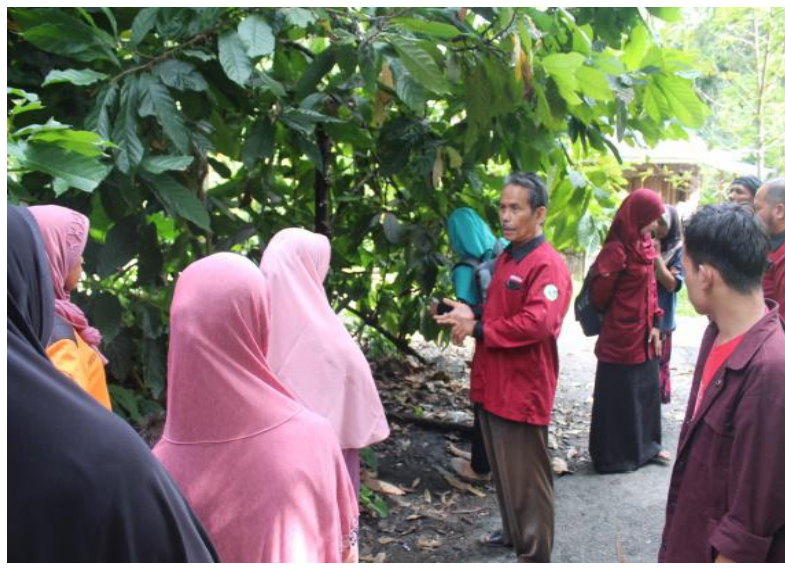

Gambar 2. Penyampaian Materi oleh Dosen Fakultas Pertanian

Pemangkasan yang benar sebaiknya melindungi cabang primer dari penyinaran matahari langsung karena dapat menyebabkan bantalan bunga menjadi mati. Menurunnya bantalan bunga pada tanaman yang tidak di pangkas dapat disebabkan persaingan unsur hara dengan daun-daun muda yang terbentuk. Selain itu, bantalan bunga pada batang dan cabang tanaman kakao banyak yang tertutupi oleh lumut sehingga bunga sulit untuk tumbuh. Pertumbuhan lumut dapat disebabkan kondisi tanaman kakao yang basah dan lembap. Adanya pemangkasan dapat menambah intensitas cahaya yang masuk ke dalam tajuk dan menurunkan kelembapan di sekitar tanaman kakao dan lumut dapat mengering sehingga bantalan bunga dapat ditumbuhi 
kembali oleh bunga kakao (Anggela dan Efendi, 2015)

Dengan adanya kegiatan pengabdian masyarakat ini masyarakat memiliki pengetahuan dari mulai cara budidaya dari tanaman kakao, cara melakukan pemangkasan secara rutin, jenis atau bentuk pemangkasan yang harus dilakukan terhadap tanaman kakao yang sedang dibudidayakan, serta cara pemeliharaan lainnya yang dapat membantu meningkatkan produksi tanaman kakao itu sendiri. Dengan demikian, perekonomian masyarakat pun meningkat.

\section{Demonstrasi Cara Pemangkasan Tanaman Kakao}

Tanaman kakao di Nagari Gunung Rajo merupakan tanaman yang telah menghasilkan, namun masyarakat disini banyak yang tidak melakukan pemangkasan terhadap tanaman budidayanya.

Demonstrasi dilakukan setelah diadakannya sosialisasi (Gambar 3). Pemangkasan merupakan salah satu teknik budidaya yang penting dilakukan dalam pemeliharaan tanaman kakao dengan cara membuang tunas-tunas liar seperti cabangcabang yang tidak produktif, cabang sakit, cabang kering, dan cabang overlapping terutama dalam hal mengatur iklim mikro yang tepat bagi pertumbuhan bunga dan buah atau untuk mengatur jumlah dan sebaran daun (Prawoto, 2008) sehingga tanaman kakao dapat memiliki kondisi yang baik untuk pertumbuhannya.

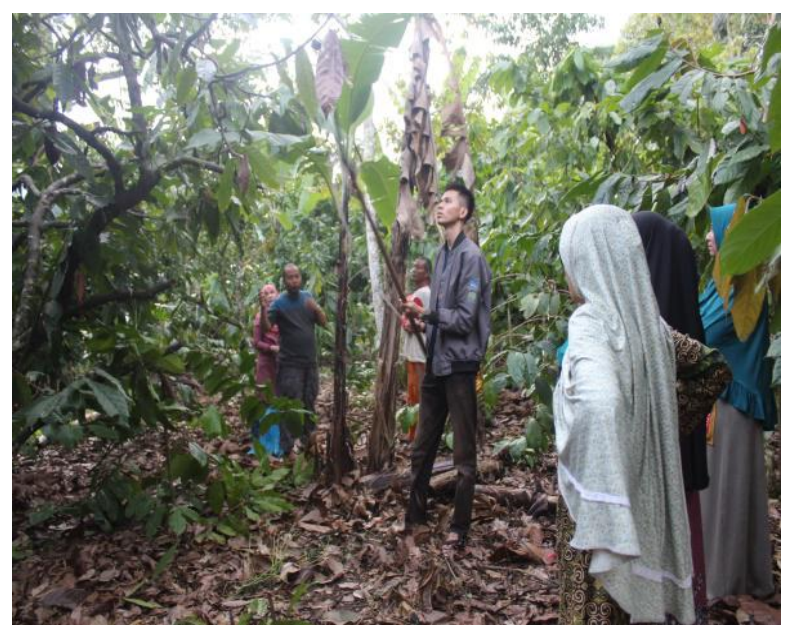

Gambar 3. Demonstrasi Cara Pemangkasan Tanaman Kakao dengan Menggunakan Alat Pemangkasan

\section{Jenis dan Waktu Pemangkasan}

Jenis pemangkasan untuk tanaman kakao terbagi menjadi tiga yaitu pemangkasan bentuk, pemeliharaan, dan produksi. Pemangkasan bentuk dilakukan untuk membentuk kerangka tanaman yang baik. Pemangkasan pemeliharaan bertujuan untuk memelihara tanaman kakao agar pertumbuhannya dapat bertahan dengan baik dan sehat dengan membuang cabang cacing, cabang yang terkena penyakit, dan cabang menggantung (Rahma, et al., 2018

Sedangkan pemangkasan produksi untuk memaksimalkan produktivitas tanaman. Pemangkasan kakao ini dilakukan dengan menggunakan ala pemangkas seperti gunting dan lain sebagainya. Dalam kegiatan demonstrasi ini, tim pengabdian 
masyarakat dari Fakultas Pertanian sekaligus juga menyerahkan alat pemangkasan sebagai bentuk apresiasi untuk masyarakat yang dapat menjadi pendorong agar masyarakat bisa melakukan kegiatan pemangkasan ini secara rutin

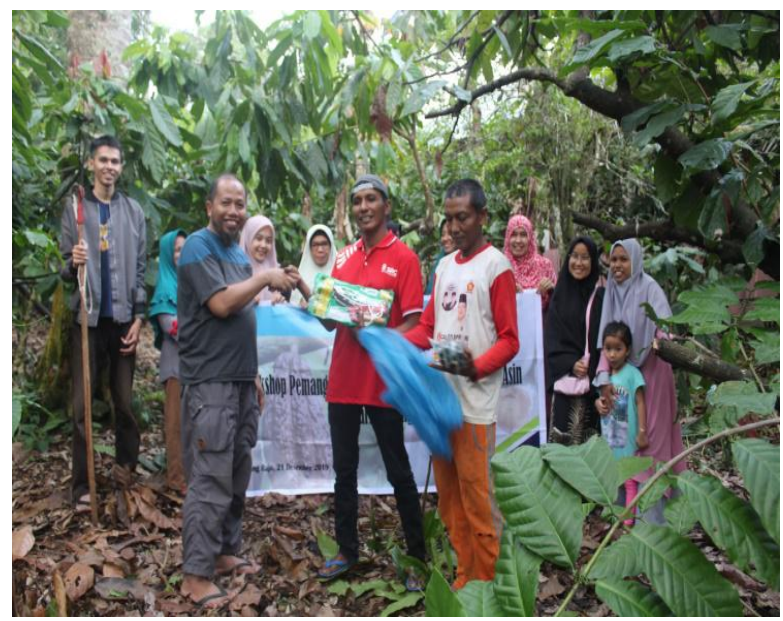

Gambar 4. Foto Bersama Sekaligus Penyerahan Alat Pemangkasan Tanaman Kakao Kepada Kelompok Tani Sawah Payo Gunung Rajo

\section{KESIMPULAN DAN SARAN}

Kegiatan ini tentang pemberdayaan masyarakat melalui kegiatan pemangkasan tanaman kakao ini sangat bermanfaat bagi masyarakat, masyarakat sangat antusias dan berpartisipasi dalam mengikuti kegiatan ini. Kegiatan ini dapat menambah pengetahuan masyarakat Nagari Gunung Rajo dalam cara budidaya tanaman kakao yang baik dan benar, mengetahui kapan waktu yang baik dilakukan pemangkasan serta jenis pemangkasan seperti apa yang akan dilakukan. Kegiatan ini sangat membantu masyarakat dalam mengatasi setiap permasalahan yang ditemukan dalam budidaya tanaman kakao tersebut serta mengetahui cara pemeliharaan yang baik. Dengan demikian secara tidak langsung sudah dapat membantu masyarakat dalam meningkatkan hasil produksi dari tanaman kakao itu sendiri, sehingga juga dapat memperbaiki perekonomian masyarakat sekitar khususnya bagi petani yang membudidayakan tanaman kakao.

\section{UCAPAN TERIMAKASIH}

Penulis mengucapkan terima kasih kepada Lembaga Penelitian dan Pengabdian Masyarakat Universitas Andalas yang telah mendanai pengabdian ini dengan no kontrak: T/30/U.N 16.17PPP.RPP/LPPM/2019 tanggal 06 Agustus 2019. 


\section{DAFTAR PUSTAKA}

Angela, T dan D. Efendi. 2015. Pengelolaan pemangkasan tanaman kakao (Theobroma cacao) di Cilacap, Jawa Tengah. Buletin Agrohorti 3 (3): 285 -293

Baon, JB., dan Abdoellah, S. 2004. Potensi lahan untuk pengembangan kakao rakyat Sumatera. Warta Pusat Penelitian Kopi dan Kakao 20 (3):104-116.

Kardiyono. 2010. Tingkatkan produktivitas kakao dengan teknologi sambung samping. Surat Kabar Berkah Edisi 257.

Karmawati, E., M. Zainal., M. Syakir., J. Munarso., K. Ardana., Rubiyo. 2010. Budidaya dan Pascapanen Kakao. Pusat Penelitian dan Pengembangan Perkebunan, Bandung. 148-152

Kementerian Pertanian. 2015. Statistik Perkebunan Indonesia 2013-2015, Kakao. Jakarta: Direktorat Jenderal Perkebunan, Kementerian Pertanian

Khairul, U., Trizelia, Reflin dan Winarto. 2018. Pemberdayaan Kelompok Tani Melalui Pelatihan Pengendalian Hama dan penyakit Tanaman Kakao di Kanagarian Campago Kabupaten Padang Pariaman. Buletin Ilmiah Nagari Membangun. Vol. 1 No. 4

Murniningtyas, E. 2011. Evaluasi Gerakan Nasional Peningkatan Produksi dan Mutu Kakao (Gernas Kakao). Bappenas, Jakarta.

Nasaruddin. 2009. Kakao. Budidaya dan Beberapa Aspek Fisiologisnya. Yayasan FOREST Indonesia. Depok. 65-68

Prawoto, A.A. 2008. Pemangkasan, Dalam T. Wahyudi, T.R. Panggabean, dan Pujiyanto (Eds). Kakao: Manajemen Agribisnis dari Hulu hingga Hilir. Penebar Swadaya, Jakarta.

Pujiyanto. 2008. Pengendalian Hama Utama, Teknik Pengamatan dan Pengendaliannya pada Tanaman Kakao, Teknik Budidaya dan Pengolahan Hasil Kakao. Puslitkoka, Jember.

Pusat Penelitian Kakao dan Kopi Indonesia. 2013. Budidaya Kakao dan Permasalahannya di Indonesia. Badan Penelitian dan Pengembangan Kementerian Pertanian Republik Indonesia

Rahma, H., Trisno, J., Martinius, M., Reflin, R., Wahyuni, S., \& Nusyirwan, N. 2018. Diseminasi teknologi pupuk kandang sapi rizobakteri pada kelompok tani kakao di Kabupaten Limapuluh Kota. Jurnal Hilirisasi IPTEKS, 1(4a): 203. 
Yanti, Y., Hamid, H., Nurbailis., Habazar, H., Nurbailis., Yaherwandi., Reflin., Nilisma. M.,dan Diandinny, A. 2019. Peningkatan Produksi Bawang Merah melalui Aplikasi Yuyaost dan Trichoderma di Kelompok Tani Ngungun Jorong Gantiang Utara. Jurnal Hilirisasi IPTEKS. 2 (4a), 333-342

Wood, GAR., Lass, LA. 1985. Cocoa. $4^{\text {th }}$ Edition. London (ENG) : Longman Group Lt. $152-153$ 